Article

\title{
Using Grey Incidence Analysis Approach in Portfolio Selection
}

\author{
Tihana Škrinjarić *(D) and Boško Šego \\ Faculty of Economics and Business, University of Zagreb, 10000 Zagreb, Croatia; bsego@efzg.hr \\ * Correspondence: tskrinjar@net.efzg.hr; Tel.: +385-1238-3325
}

Received: 4 November 2018; Accepted: 20 December 2018; Published: 23 December 2018

\begin{abstract}
Due to the development of financial markets, products, financial and mathematical models, portfolio selection today represents a comprehensive set of activities. Investors take into consideration many different factors, such as the market factors, return distribution characteristics and financial statements information. This research applies a Grey Relational Analysis (GRA) approach to evaluate the performance on a sample of stocks by taking those different factors into consideration. The results based upon a sample of 55 stocks for the trading year 2017 on the Croatian capital market show that using GRA approach in portfolio selection provides useful guidance for investors when making investment decisions, and better portfolio results in terms of risk and return are reachable compared to an equally weighted portfolio benchmark.
\end{abstract}

Keywords: portfolio selection; Grey Relational Analysis; stock market; financial ratios; market data; performance measurement

\section{JEL Classification: C61; G11}

\section{Introduction}

Portfolio selection today represents a very difficult task in portfolio management due to many investment possibilities on the financial markets, many factors influencing the investors' decisions and constant dynamic changes on the markets as well. Investors have to make daily decisions based upon different information. Thus, a quality decision making process should be supported with quantitative modelling which can ease this process and achieve investment goals. Utility function theory has been developed regarding an investor's utility being based upon first $m$ moments of return distributions (see Jurczenko and Maillet 2005) explaining that investors make their decisions based upon those distribution moments. Moreover, many studies have shown that financial ratios data are useful in portfolio management as well (Chen and Thomas 1981; Singh and Schmidgall 2002). In that way, many different methodologies in mathematics and econometrics have been developed in order to provide some of the answers to investor's questions regarding stock performance and portfolio selection. Some of the most popular approaches to deal with large amounts of information include Data Envelopment Analysis (see Chen 2008 or Dia 2007), Multicriteria Decision Analysis (Steuer et al. 2008 or Edirisinghe and Zhang 2007) and Multivariate analysis (clustering, principal components analysis and similar approaches, see Korzeniewski 2018). However, a relatively unknown and new approach is the Grey Relational Analysis (GRA) approach. This methodology, i.e., the wider term Grey Systems, was firstly developed in the field of modelling uncertain systems and it was applied over different areas such as decision making processes, ecological, hydrological, geological and similar systems (see Liu et al. 2016 for the history development and different areas of applications). The novelty and contribution of this research is applying the GRA approach in the decision making process in portfolio selection, since this approach is found to be extremely rare in financial applications, especially when making decisions on 
the structure of the stock portfolio. The results from GRA approach ranking of stocks is used for the simulation of portfolio investing, an approach which is also rarely found in applications. Moreover, the contribution of this study compared to existing ones is in providing the rationale of why we include chosen variables, i.e., factors in the modelling procedure, based upon financial theory and empirical findings over decades. This is in the majority cases ignored in the empirical applications.

Thus, the main goal of this study is to empirically evaluate market and financial statement data on a sample of stocks by using the GRA approach in order to obtain information on whether this approach could be applicable to portfolio selection. This will be achieved by comparing the portfolios which are a result from taking into consideration the best stocks from the GRA ranking system in sample and by comparing the out of sample performances of simulated portfolios in the empirical analysis. The GRA approach of evaluating performance has several advantages compared to other approaches such as Data Envelopment Analysis, Analytic Hierarchy Process and other approaches: it is not sensitive to data transformations, easier estimations are available, and straightforward interpretations can be made, etc. (Wei 2011). Thus, two main research questions are as follows. First, can the Grey Relational Analysis provide a useful guidance for investors when making investment decisions? This question asks if results given with one number from the GRA provides useful information on how to form stock portfolios. The second question is whether portfolios formed based upon the GRA approach can provide better results in terms of risk and return compared to a simple benchmark (equally weighted portfolio).

The rest of the paper is structured as follows. The second section deals with previous related research. The third section describes the methodology used in the study. Results and discussion are given in the fourth, fifth and sixth sections. The final section concludes the paper.

\section{Previous Research}

By analyzing previous existing research which applies the GRA approach in finance, it can be seen that there is a great scarcity of research in this area. The majority of the applications were made in different fields (see Liu and Lin 2010).

Huang et al. (2008) combined weight clustering model with the K-means Clustering approach and the Grey Systems Theory with the Rough Set theory in order to create automated stock market forecasting with portfolio selection on the Taiwanese market for the period 1Q2003-4Q2016. Authors thus apply a dynamic analysis in which in every quarter they collect financial data on selected stocks and cluster them by using K-means clustering. Finally, the GRA approach is used to rank the stocks and include the portfolios. The results indicate that such formed portfolios obtain significant returns over the observed period. It can be seen in this research that authors observe those investors who only aim at the greatest returns possible. Several financial ratios were chosen in the research and rationale is based upon investment principles advocated by W. Buffett, as authors' state. Huang and Jane (2008) extended this research by combining Fuzzy C-means theories with Variable Precision Rough Set theory when comparing stocks with the Average Autoregressive Exogenous prediction model of the future stock market movements. The GRA analysis was also used to specify the weighting of the selected stocks, with the same approach as in the previous paper, to achieve maximum rate of return. Again, a dynamic analysis was performed for the period 2004 until 2006 based upon quarterly data and financial ratios. Here, the authors do not state why they used the financial data which was included in the empirical research. However, the authors conclude based upon the results that such combination of the aforementioned approaches leads to achieving great portfolio rate of returns.

Li et al. (2010) combine the AHP (Analytic Hierarchy Process) methods for the stock selection on 8 listed companies within the steel industry on the Chinese stock market. There is no time span stated in the research, and authors use the following factors to rank stocks: profitability (profit margins and net profit margins), profit and sales growth rates, earnings per share, price to earnings ratio, solvency ratios and operating ability ratios. The approach in this study is to obtain weights via AHP for the second step of GRA and conclude that the results are promising. However, no investment decisions 
were applied in order to compare portfolio results. Jane and Huang (2013) focus again on the automatic stock selection mechanism, this time by combining Artificial Neural Network with the GRA modelling. All companies listed on the Taiwanese market in the period from November 2008 until April 2013 were used for comparison purposes. The results were very promising with obtaining extraordinary results as in Huang and Jane (2008). Salardini (2013) combines the AHP and GRA approaches on the sample of 16 stocks on Tehran Stock Exchange in year 2010. Both approaches were used in order to obtain optimal weights in the ranking system. Stocks were ranked based upon several factor, but no explanation is given for the usage of chosen variables. Mohammadi Pour et al. (2016) is one of the last to apply GRA analysis on the stock selection process. Authors compared 14 stocks from the Tehran Stock Exchange for the period 2009-2014. In total 4 financial ratios were used in the study (with no explanations on why those) and rankings were made and compared to the Johnson forecasting ranking. Results indicated similar ranking results for both methods.

As can be seen from the literature overview, not many studies exist within this field. Moreover, portfolio selection as in terms of risk diversification was not observed as well. Finally, not many papers include explanations and rationale from the financial theory standpoint which factors should be included in the analysis. This is why this research is trying to fill that gap.

\section{Methodology}

For describing the methodology used in this study, we follow Liu and Lin $(2006,2010)$. This methodology was firstly developed in Deng (1982) and since then it was applied in different areas of research (for overview, please see Deng 1989; Liu et al. 2016). This approach of modelling is used to build a ranking system of alternatives in order to choose the best one. Denote with $\left(x_{i}(1), x_{i}(2), \ldots, x_{i}(n)\right)$ the behavioural sequence of the $k$-th factor, $k \in\{1,2, \ldots, n\}$ for observed alternatives $i \in\{1,2, \ldots, m\}$. All of the data can be formatted into the matrix $X$ :

$$
X=\left[\begin{array}{cccc}
x_{1}(1) & x_{1}(2) & \cdots & x_{1}(n) \\
x_{2}(1) & x_{2}(2) & & x_{2}(n) \\
\vdots & \vdots & \ddots & \vdots \\
x_{m}(1) & x_{m}(2) & \cdots & x_{m}(n)
\end{array}\right]
$$

The data is normalized so a comparability sequence can be obtained: $\left(y_{i}(1), y_{i}(2), \ldots, y_{i}(n)\right)$, with normalization accordingly to rules of data being the greater (larger) the better:

$$
y_{i}(k)=\frac{x_{i}(k)-\min _{i} x_{i}(k)}{\max _{i} x_{i}(k)-\min _{i} x_{i}(k)},
$$

the smaller the better:

$$
y_{i}(k)=\frac{\max _{i} x_{i}(k)-x_{i}(k)}{\max _{i} x_{i}(k)-\min _{i} x_{i}(k)},
$$

or the closer to the desired value $x^{*}(k)$ the better:

$$
y_{i}(k)=\frac{\left|x_{i}(k)-x^{*}(k)\right|}{\max _{i} x_{i}(k)-x^{*}(k)}
$$

Normalization could be made by dividing each value for factor $k$ by the first value $x_{1}(k)$ as well. When using expressions (2) and (3) to normalize data, every new value will be within the interval [0, 1]; and the greater the normalized value is, the closer is the original value to the minimum or maximum, depending on the criteria. In order to calculate the Grey Incidence Index, absolute differences are calculated compared to the referent value $y^{*}(k)$ :

$$
\Delta y_{i}(k)=\left|y^{*}(k)-y_{i}(k)\right|
$$

Kuo et al. (2008) define the reference sequence as all values $y^{*}(k)$ being equal to one. The Grey Relational Coefficient is calculated as: 


$$
G_{i}(k)=\frac{\Delta_{\min }+p \Delta_{\max }}{\Delta y_{i}(k)+p \Delta_{\min }},
$$

where $p$ is the distinguishing coefficient, $0 \leq p \leq 1 ; \Delta_{\min }=\min \left\{\Delta y_{1}(k), \ldots, \Delta y_{m}(k)\right\} \forall k ; \Delta_{\max }=$ $\max \left\{\Delta y_{1}(k), \ldots, \Delta y_{m}(k)\right\} \forall k$. Finally, the Grey Relational Degree (Relational Grade) for each alternative is a weighted average of relational coefficients for different factors:

$$
r_{i}=\sum_{i=1}^{n} w_{i} G_{i}(k), \quad \forall i
$$

where weights $w_{i}$ satisfy the condition: $\sum_{i=1}^{n} w_{i}=1$. The Grey Relational Grade in (7) for each alternative is interpreted as the degree of similarity between the reference sequence of $y^{*}(k)$-s and the alternatives being compared to it. In some literature it is interpreted as the correlation coefficient. Thus, the greater the value of $r_{i}$ for an observed alternative, the better the performance it is considered to have compared to others. As it can be seen, this approach is relatively simple, straightforward and directly interpretable. More details can be seen in Liu et al. (2016).

\section{Empirical Results}

\subsection{Data Description and Rationale for Used Factors}

For the purpose of the empirical analysis, daily price data on most liquid ${ }^{1}$ stocks on the Croatian stock market, Zagreb Stock Exchange (ZSE 2018) was collected for the year 2017. Most liquid stocks are observed in order to have as much as data possible. In that way, the sample consists of 55 stocks in total. Moreover, additional data on return series was collected in the first half of 2018 for the out of sample calculations and comparisons (see Section 5). Moreover, several financial ratios for each stock have been obtained from financial statements of 2017 as well. In that way, the analysis can be undertaken based upon the newest data possible. Thus, the analysis will include ranking of the stocks based upon the return distribution characteristics, as well as on financial statements of each company. Based upon the daily prices, daily continuous returns were calculated and average return for the 2017 was calculated for each stock. Next, standard deviations as a risk measure and coefficients of asymmetry and kurtosis were calculated as well for each stock. It is assumed that investors base their decisions on investing based upon the first $m$ moments of return distribution. As Arditti (1967) discussed: investors prefer positive skewness of returns as a result of decreasing absolute risk aversion; and the famous theorem of Müller and Machina (1987, p. 351) which states that investors with von Neumann-Morgenstern utility functions rank probability distributions on the basis of their first $\mathrm{m}$ absolute moments. Based upon the investor's utility function theory, in the analysis we assume that investors prefer higher odd moments of return distribution (first and third moments: average return and skewness), whilst they prefer smaller event moments (second and fourth moments: standard deviation and kurtosis). For more details on investor's utility functions discussion and preferences towards the $m$ moments of return distribution please see Arditti and Levy (1975), Athayde and Flôres (1997), Hwang and Satchell (1999), Briec et al. (2006), Jurczenko and Maillet (2005), Jondeau and Rockinger (2006) or Gardijan and Škrinjarić (2015).

Two liquidity measures used in the study, trading volume and number of transactions, are referred to as market measures. Previous literature finds negative relationship between the liquidity premium and stock returns (Datar et al. 1998; Pástor and Stambaugh 2003; Liu 2006; Hur et al. 2018; Hur and

1 Liquid in terms of number of transactions. Although research exists on how (il)liquidity affects stock returns, here we include more liquid stocks due to having more data to make calculations with. In 2017, in total 93 stocks were traded on ZSE. Problems with liquidity are not something new for ZSE. Namely, as Škrinjarić (2018a) states: in the period from September 2014 until May 2018, there were only 9 stocks which were traded at least $90 \%$ of the time, 17 with $75 \%, 25$ with $60 \%$ and 37 with $30 \%$ of the whole period. The usual approach is to pick the liquid stocks which have been traded most frequently in a period. More details can be seen in Škrinjarić (2018b) or Vidović (2013). 
Chung 2018). Thus, the approach in this research is that investors aim for lower liquidity in order to obtain illiquidity premiums. Inclusion of financial statements data is based upon previous research which finds that there exist differences in stock returns depending upon financial ratios. Basu (1977) was one of the first studies to find that firms with a small price to earnings (PE) ratio had higher returns compared to other firms on the US market in the long term. Shiller (2005) showed that long-term investors should focus on lower PE ratios, whilst in short term it is possible to obtain excess returns with higher PE ratios. Since we observe a short-term in this study, we focus on greater PE ratios. Book to market ratio (BM) was extensively studied over the last couple of decades. Banz (1981) and Reinganum (1981) were some of the first studies to conclude that smaller stocks have greater returns compared to bigger ones. This stimulated Fama and Fama and French $(1992,1993,1995,1996)$ to include this ratio into their famous 3-factor model and found a strong positive effect of BM ratio on cross-sectional stock returns. That is why we are aiming for a greater value of this ratio in the analysis. Furthermore, $\mathrm{Wu}(2000)$ conducted a survey of institutional and individual investors and found that earnings per share (EPS), return on assets (ROA) and liquidity ratios are some of the most used financial ratios when investors make their investment decisions in practice. This was confirmed in Muhammad and Scrimgeour (2014), who add return on equity (ROE) to this list as well and conclude that these ratios give information to investors on effective and efficient usage of the firm's assets and equity in order to generate profits. Moreover, investors should aim towards greater value of mentioned ratios due to them being a proxy for performance measurement of firms and efficiency of their management. That is why investors should aim greater values of EPS, ROA and ROE (evidence was found as well as in Dimitropoulos and Asteriou (2009) and Palepu and Healy (2010)). Finally, the positive relationship between the Dividend per Share (DPS) ratio and expected returns has been found very early in the literature in work of Fama and Schwert (1977) and Campbell (1987); and has been continuously confirmed over the years as well in Fama and French (1988), Campbell and Shiller (1988), Kothari and Shanken (1997) or Lewellen (2004).

Table A1 in Appendix A depicts the used factors in the study, with their abbreviations in brackets and the preferred values of each factor. If investor should prefer higher value, a plus sign is added; and opposite is true for those factors which should be lower. Table 1 shows the average, minimum and maximum value of each factor in the analysis. It can be seen that the values vary significantly. However, due to the many factors upon which to base investment decisions, the GRA approach seems appropriate.

Table 1. Average, minimum and maximum values of factors for the whole sample.

\begin{tabular}{cccc}
\hline Factor & Average & Min & Max \\
\hline SD & 0.020 & 0.003 & 0.073 \\
CS & 23.570 & 3.194 & 127.755 \\
TV & $637,612.691$ & 800.000 & $7,892,835.000$ \\
NT & 2914.218 & 260.000 & $16,276.000$ \\
ER & 0.000 & -0.003 & 0.003 \\
CA & 0.722 & -6.847 & 9.195 \\
BM & 2.923 & 0.001 & 78.930 \\
PE & 5.121 & -30.875 & 79.841 \\
ROA & 0.428 & -2.230 & 26.362 \\
ROE & -0.343 & -50.453 & 68.125 \\
EPS & 1584.294 & 0.028 & $45,894.157$ \\
TBR & 1.047 & 0.201 & 2.673 \\
ATR & 7.926 & 0.007 & 208.657 \\
DPS & 41.831 & 0.000 & 1649.937 \\
\hline
\end{tabular}

SD-standard deviation; CS-coefficient of skewness; TV-trading volume; NT-number of transactions; ER-expected return; CA—coefficient of asymmetry; $\mathrm{BM}$ - book to market ratio; PE-price to earnings ratio; ROA—return on assets; ROE—return on equity; EPS — earnings per share; TBR—-total business efficiency ratio; ATR — asset to earnings ratio and DPS—dividend per share. Source: authors. 


\subsection{Results in Sample}

Firstly, based upon the signs in Table A1 (in Appendix A), each factor was normalized by using Formulas (2) and (3). The distinguishing coefficient was chosen ranging from 0.1 to 0.9 and the results of the degrees of grey incidence for each stock. Since the ranking does not change with respect to the distinguishing coefficient (see Figure 1), Table 2 is showing Grey relational grades for the value of the coefficient being 0.5 . This could be interpreted as the correlation between the performances of each stock with respect to all factors to the optimal value of 1 for each factor. Moreover, here we have chosen equal weights for all of the factors in the analysis as a starting point. This means that it is assumed that investors are regarding all of the information (factors) on stocks in an equal manner. It can be seen that the best stocks in terms of performance in Table 2 are TUHO, MDKA, ATLN, LKRI and LPLH, due to them having the greatest values of degree of incidence. The worst performance had LEDO, OPTE, DDJH, DLKV and INGR. This conclusion is robust when changing the distinguishing coefficient, as it can be seen on Figure 1. Thus, from an initial larger sample of stocks available, investor can use this information to narrow his set of interesting stocks to evaluate further or to invest in the best performing stocks.

Table 2. Grey relational grade for each stock, distinguishing coefficient value is 0.5 .

\begin{tabular}{cccc}
\hline Stock & $p=\mathbf{0 . 5}$ & Stock & $p=0.5$ \\
\hline ADPL & 0.5303 & KRAS & 0.5418 \\
ADRS & 0.5401 & LEDO & 0.4358 \\
ADRS2 & 0.5213 & LHRC & 0.5535 \\
ARNT & 0.5276 & LKPC & 0.569 \\
ATGR & 0.5364 & LKRI & 0.5771 \\
ATLN & 0.5886 & LPLH & 0.5746 \\
ATPL & 0.518 & LRH & 0.5652 \\
AUHR & 0.5224 & MAIS & 0.5454 \\
BD62 & 0.5205 & MDKA & 0.5889 \\
BLJE & 0.4855 & OPTE & 0.4592 \\
CKML & 0.5406 & PLAG & 0.5526 \\
DDJH & 0.461 & PODR & 0.5417 \\
DLKV & 0.4702 & PTKM & 0.4829 \\
ERNT & 0.5224 & RIVP & 0.511 \\
HDEL & 0.5152 & RIZO & 0.5229 \\
HHLD & 0.5104 & SAPN & 0.533 \\
HMST & 0.5458 & SLRS & 0.5356 \\
HT & 0.4984 & THNK & 0.4873 \\
HUPZ & 0.4959 & TPNG & 0.5398 \\
IGH & 0.4874 & TUHO & 0.6111 \\
INA & 0.5435 & ULPL & 0.5248 \\
INGR & 0.4778 & ULJN & 0.514 \\
IPKK & 0.5242 & VART & 0.5281 \\
JDGT & 0.5255 & VIRO & 0.521 \\
JDPL & 0.5139 & VLEN & 0.5076 \\
JMNC & 0.5269 & ZB & 0.5198 \\
JNAF & 0.5537 & ZVZD & 0.5389 \\
KOEI & 0.5477 & & \\
\hline
\end{tabular}

Source: authors. 


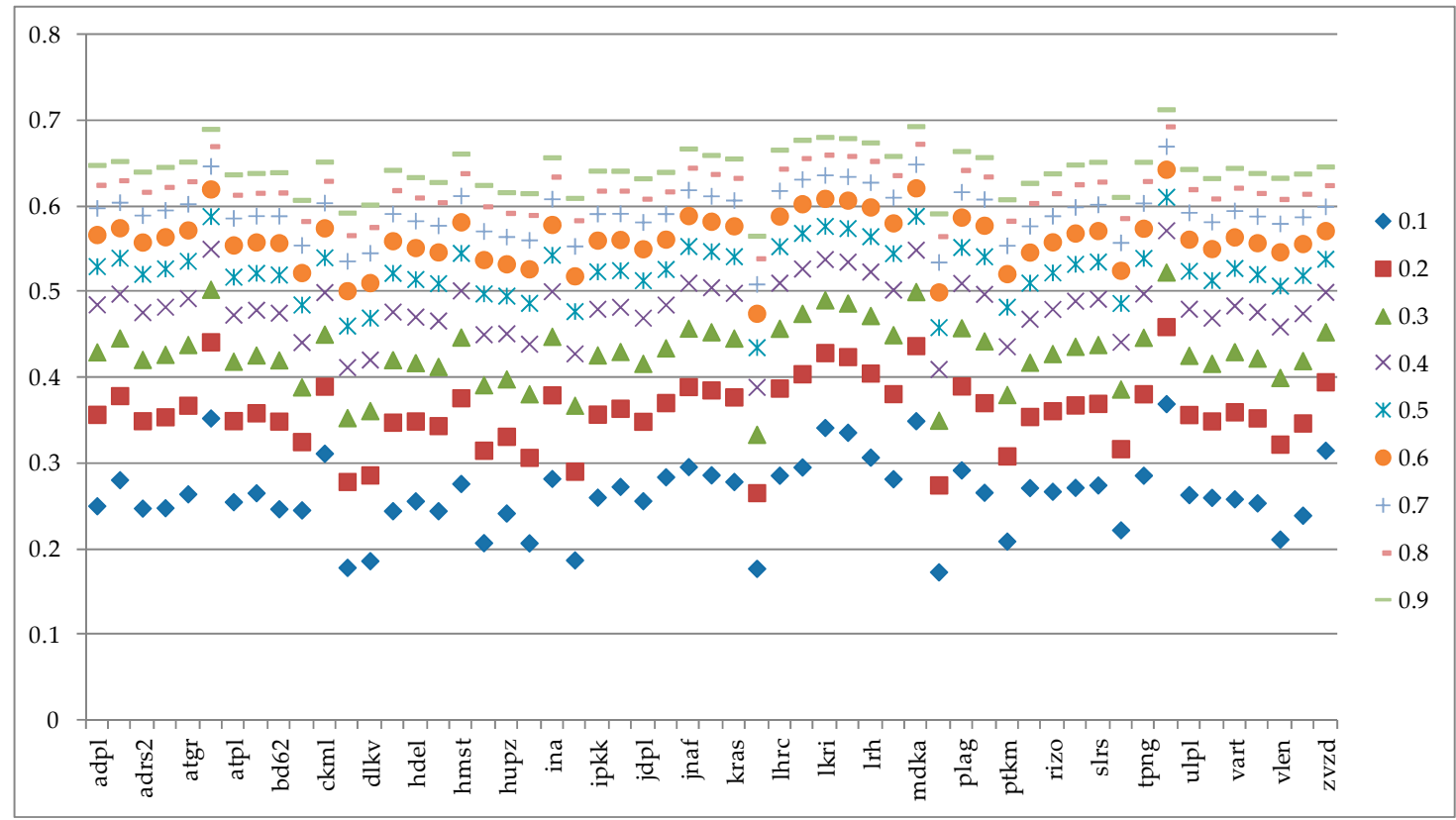

Figure 1. Grey relational grades for the analyzed stocks, different values of distinguishing coefficients.

In order to obtain more information on the usefulness of using the GRA approach, an additional ranking was made based upon several other criteria. In the first scenario it is assumed that an investor regards only the first two moments of return distribution equally and gives them equal weight. Moreover, the investor ignores all other factors. This scenario is denoted "2 moments". Other scenarios include: investor equally weights only the first three moments ("3 moments"); first four moments ("4 moments"); only the financial ratios data ("only financial"); major weight is given to the risk ( $50 \%$, whilst other $50 \%$ is equally distributed to all other factors; "risk"); major weight is given to the return ( $50 \%$, whilst other $50 \%$ is equally distributed to all other factors; "return") and final scenario in which $70 \%$ of the weight is given to return distribution moments, whilst other $30 \%$ to other factors (named "0.7 moments; 0.3 other"). Thus, the whole procedure of calculation was performed again and the Grey incidence indices are compared on Figure 2. Although it seems that for many cases the ranking remained the same, some major differences arise when investors change their preferences. The detailed ranking is shown in the Appendix A, in Table A3. Some major differences occur for, e.g., stock ZVZD, which was ranked the best according to the scenarios " 3 moments" and "return", but is almost the worst (53 rank out of 55) when taking into account scenario "risk". Thus, the ranking will depend upon investor's preferences and subjective goals.

We wanted to obtain information whether this ranking system can provide a successful portfolio selection in terms of risk and return, by constructing efficient frontiers in terms of the Markowitz portfolio (Markowitz 1952, 1959). Firstly, an original efficient frontier was constructed based upon the whole sample in order to compare how closely the investor can approach this frontier with the analysis of GRA approach. This is depicted on Figure 3 and denoted with "efficient frontier". This original frontier was constructed based upon varying the risk in the Markowitz (1959) model from the minimum variance portfolio until the portfolio with the maximum return.

Next, based upon the rankings on Figure 2, several frontiers were constructed as a second step of the whole analysis. Notation is the same as on Figure 2. However, these frontiers are not efficient in terms of the Markowitz model, due to them being constructed based upon several points: the first point was constructed such that weights to individual stocks were constructed based upon the grey incidence indices. Every weight is equal to the value of the individual index divided by the total sum. In that way, all of the stocks entered the portfolio. The second point was constructed by giving equal weights to the first 3 best stocks based upon the grey indices. The third point was constructed by giving equal weights to the first 5 best stocks based upon the same indices. In that way, we wanted to observe 
how the point changes from the starting value when all of the stocks are included in the portfolio. By undertaking this analysis, we can obtain information if the portfolio goes closer to the Markowitz efficient frontier or away from it. ${ }^{2}$ As can be seen on Figure 3, interesting results arise, depending upon what investor takes into consideration. The best approach in this analyzed sample was for all of those scenarios which included portfolio moments, due to these frontiers expanding towards the original efficient frontier. The worst performance was obtained for only financial data. This means that in this observed period, if investors based their analysis mostly on the return distributions, they could have formed such portfolios to obtain good results in terms of portfolio risk and return. On the other hand, the inclusion of financial data did not result in desiredoutcomes. However, it can be seen as well that when the portfolios are compared to the equally weighted portfolio (denoted with "equally w portfolio"), investor can achieve better results (greater return and/or smaller risk) with respect to this benchmark.

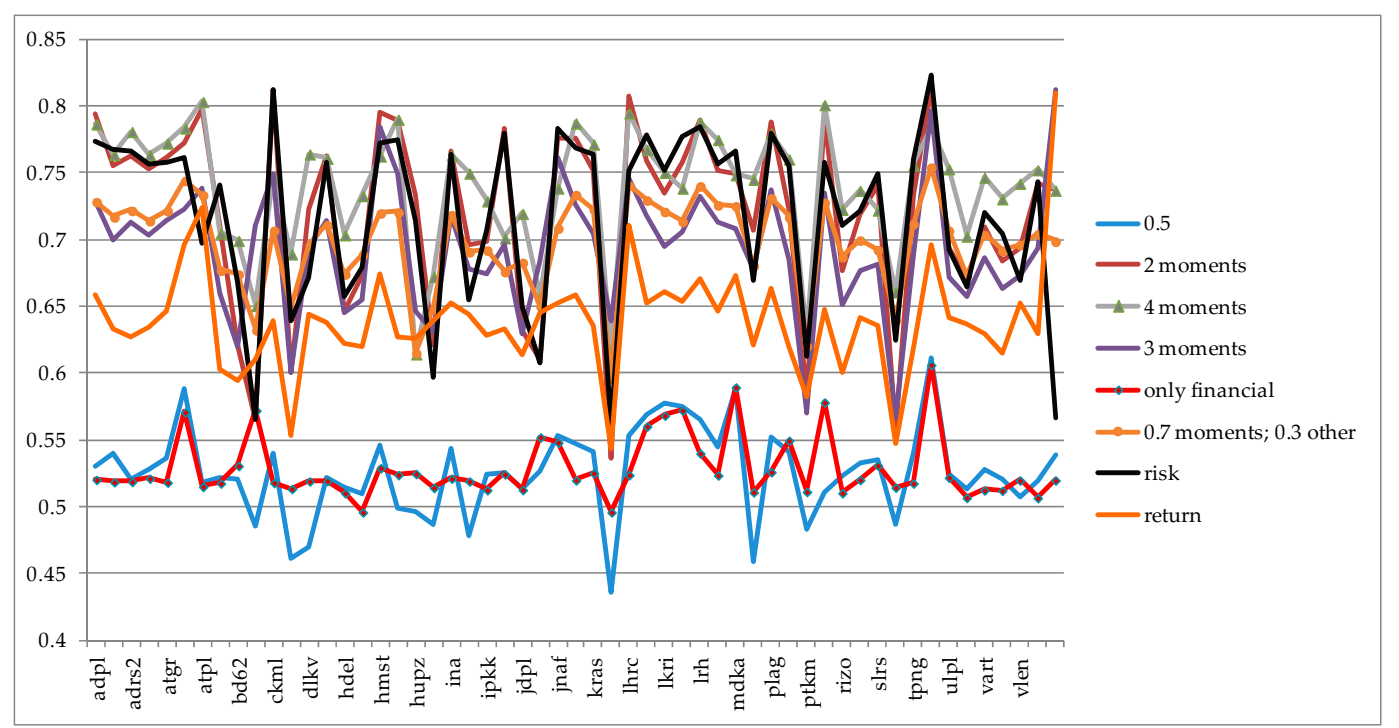

Figure 2. Grey relational grades for the analyzed stocks, different criteria.

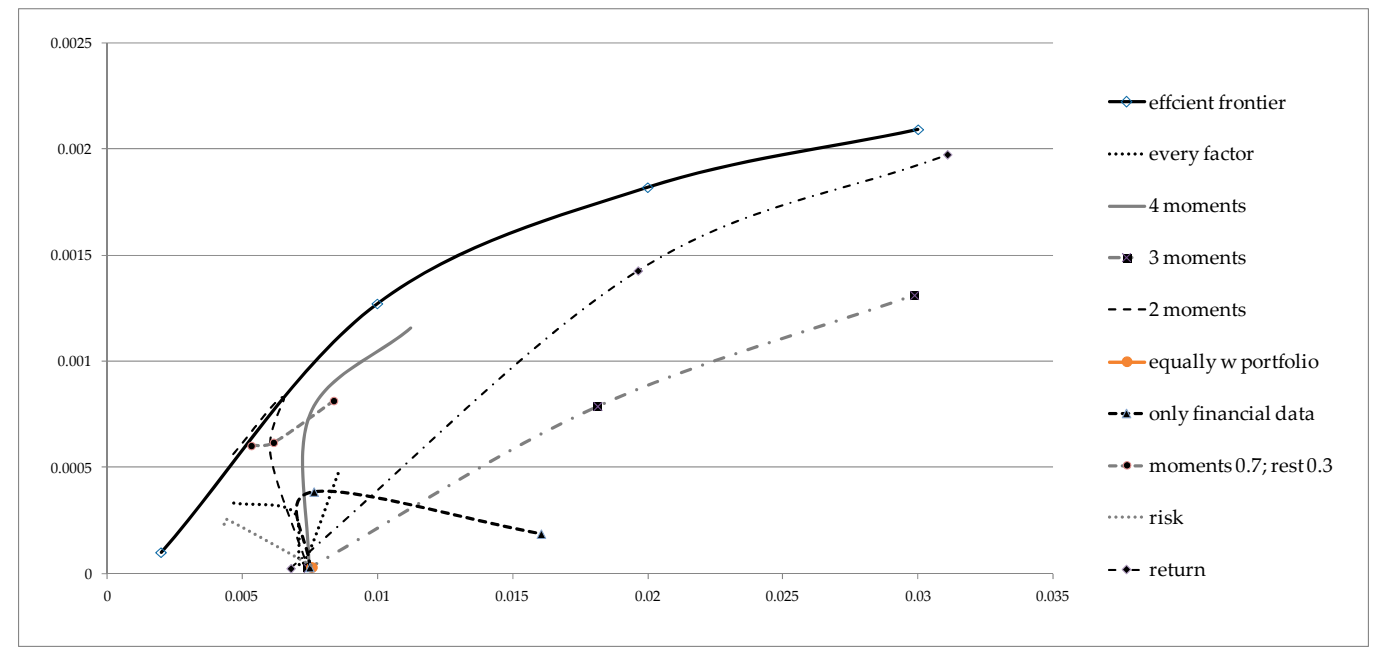

Figure 3. Comparison of efficient frontier with other frontiers, fixed weights of stocks in portfolios.

2 Moreover, we do not choose to invest only in the best stock, due to diversification possibilities within Modern Portfolio Theory. 
Finally, we wanted to construct efficient frontiers for the best performing scenarios from Figure 3 in the Markowitz spirit. Thus, additional models were optimized in which stock weights were obtained for the best performing 3, 5 and 10 stocks by the ranking in Table A2. Now, all of the frontiers are efficient in terms of Markowitz portfolio optimization, where we change the risk of the portfolio ranging from the minimum variance portfolio until the maximum return. The efficient frontiers are shown on Figure 4 . It can be seen that " 2 moments" and " 4 moments" efficient frontiers are very close to the original frontier; meaning that ranking stocks based upon return distribution moments gives insights for investing into more efficient portfolios, especially compared to the equally weighted portfolio (denoted with "equal weights"), at least in sample.

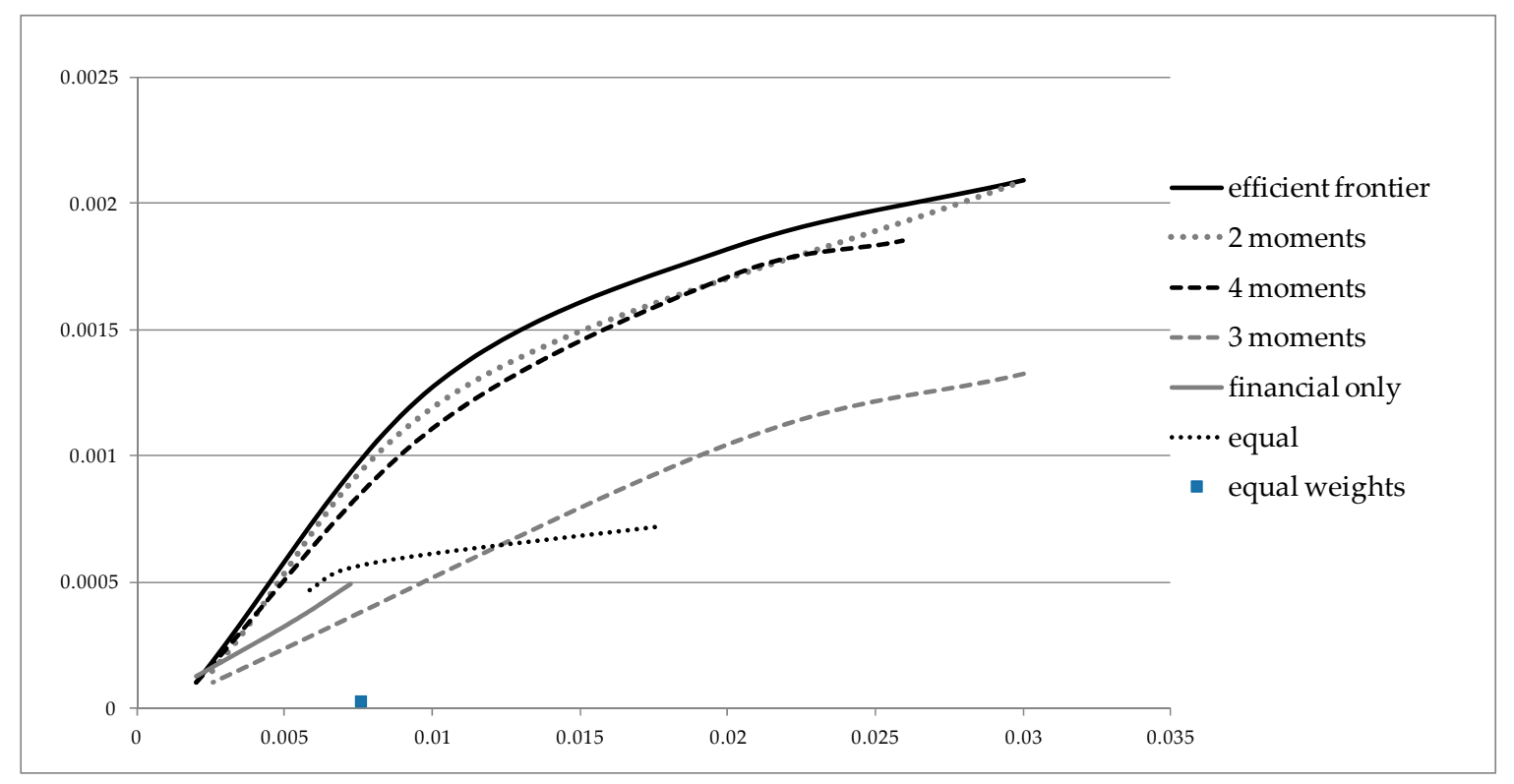

Figure 4. Comparison of efficient frontiers, optimization resulted weights.

\section{Backtesting Portfolio Results}

Now we focus on the out of sample results by performing backtesting of the portfolios constituting the efficient frontiers on Figure 4 in order to evaluate the performance based upon ranking from the GRA approach. The performance measures are calculated based upon the Knight and Satchell (2002) performance measurement book. It is assumed that an investor uses the GRA ranking system results from Table A2 in order to construct portfolios at the beginning of 2018 and holds those portfolios until mid 2018. For every efficient frontier from Figure 4, we extracted 4 portfolios: minimum variance, maximum return and two in between to represent different risk aversions in the analysis. Thus, in total we observe 24 different portfolios and the equally weighted one as well. The characteristics of those portfolios are given in Table 3. It can be seen that regarding the realized return, the best portfolio in total was the one where equal weights were given to all of the criteria in the GRA ranking system with the return maximization approach. In general, the " 2 moments" portfolios obtained the best results regarding the realized returns, due to having positive returns on for all of the selected portfolios. In terms of risk, the overall best performing were the "Financial only" criteria portfolios. However, investors observe these measures in combination and not separately. That is why firstly we compare Sharpe ratios for every portfolio in order to obtain reward to risk ratios. It can be seen that in general, the " 2 moments" portfolios achieve greatest (positive) values of the Sharpe ratio, especially when investors aim to maximize the portfolio returns. The " 3 moments" portfolios obtained the worst performance regarding this ratio out of sample. This is somewhat in line with Figure 4 where the "3 moments" frontier was the farthest from the original efficient frontier, while the " 2 moments" frontier was the closest. 
Table 3. Comparison of performances of simulated portfolios in 2018.

\begin{tabular}{|c|c|c|c|c|c|c|c|c|}
\hline \multirow{2}{*}{\multicolumn{2}{|c|}{ Portfolio }} & \multirow{2}{*}{$\begin{array}{c}\text { Realized } \\
\text { Return (\%) }\end{array}$} & \multirow{2}{*}{$\begin{array}{c}\text { Standard } \\
\text { Deviation (\%) }\end{array}$} & \multirow{2}{*}{$\begin{array}{l}\text { Sharpe } \\
\text { Ratio }\end{array}$} & \multicolumn{4}{|c|}{ Certainty Equivalent (CE) } \\
\hline & & & & & 1 & 2 & $\begin{array}{c}3 \\
\text { mom }\end{array}$ & $\begin{array}{c}4 \\
\text { mom }\end{array}$ \\
\hline \multirow{4}{*}{$\begin{array}{l}\text { Efficient } \\
\text { frontier }\end{array}$} & Min risk & 0.827 & 0.462 & 1.399 & 0.008 & 0.008 & 0.347 & 1.777 \\
\hline & Portfolio 1 & 0.827 & 0.462 & 1.788 & 0.008 & 0.008 & 0.347 & 1.777 \\
\hline & Portfolio 2 & -3.567 & 3.455 & -1.032 & -0.036 & -0.037 & -0.679 & -0.880 \\
\hline & Max return & -5.152 & 4.520 & -1.140 & -0.053 & -0.054 & -0.766 & -1.038 \\
\hline \multirow{4}{*}{2 moments } & Min risk & 0.941 & 0.797 & 1.181 & 0.009 & 0.009 & 0.442 & 1.724 \\
\hline & Portfolio 1 & 1.382 & 0.713 & 1.937 & 0.014 & 0.014 & -0.084 & 1.194 \\
\hline & Portfolio 2 & 2.024 & 0.755 & 2.681 & 0.020 & 0.020 & 0.143 & 1.695 \\
\hline & Max return & 5.917 & 1.388 & $4.262 *$ & 0.059 & 0.059 & -0.194 & -1.081 \\
\hline \multirow{4}{*}{3 moments } & Min risk & 0.197 & 0.591 & 0.333 & -0.044 & -0.044 & 0.025 & 0.594 \\
\hline & Portfolio 1 & -2.660 & 1.067 & -2.493 & -0.018 & -0.018 & 0.714 & 1.778 \\
\hline & Portfolio 2 & -1.792 & 0.746 & -2.403 & -0.027 & -0.027 & $0.747 *$ & $1.845 *$ \\
\hline & Max return & -4.367 & 1.817 & -2.403 & -0.002 & -0.002 & 0.721 & 1.819 \\
\hline \multirow{4}{*}{4 moments } & Min risk & -0.223 & 0.952 & -0.235 & -0.002 & -0.002 & 0.304 & -0.178 \\
\hline & Portfolio 1 & 2.790 & 0.951 & 2.935 & 0.028 & 0.028 & -0.927 & -1.336 \\
\hline & Portfolio 2 & -0.563 & 2.597 & -0.217 & -0.006 & -0.006 & -0.590 & -0.850 \\
\hline & Max return & -6.778 & 5.960 & -1.137 & -0.070 & -0.071 & -0.784 & -1.057 \\
\hline \multirow{4}{*}{ Financial only } & Min risk & 0.311 & 0.615 & 0.506 & -0.044 & -0.044 & -0.850 & -1.353 \\
\hline & Portfolio 1 & 0.196 & 0.383 & 0.512 & 0.002 & 0.002 & -0.851 & -1.352 \\
\hline & Portfolio 2 & 0.161 & 0.319 * & 0.505 & 0.002 & 0.002 & -0.848 & -1.343 \\
\hline & Max return & -4.367 & 1.817 & -2.403 & 0.003 & 0.003 & 0.721 & 1.819 \\
\hline \multirow{4}{*}{ Equal } & Min risk & -1.677 & 0.812 & -2.065 & -0.017 & -0.017 & -1.395 & -2.722 \\
\hline & Portfolio 1 & 1.371 & 1.017 & 1.349 & 0.014 & 0.014 & -1.456 & -2.713 \\
\hline & Portfolio 2 & 3.888 & 1.684 & 2.309 & 0.039 & 0.039 & -0.751 & -1.010 \\
\hline & Max return & $7.977 *$ & 3.065 & 2.602 & $0.079 *$ & $0.079 *$ & 0.262 & 0.793 \\
\hline Equal weights & - & 0.470 & 0.593 & 0.793 & 0.005 & 0.005 & -0.441 & 0.135 \\
\hline \multicolumn{9}{|c|}{$\begin{array}{l}\text { Note: greatest return, minimal risk, greatest Sharpe ratio }{ }^{3} \text { and greatest Certainty Equivalent for each category of } \\
4 \text { portfolios is in bold and the values with asterisks are denoted as being best in respective rows. Numbers } 1 \text { and } 2 \\
\text { denote the coefficient of absolute risk aversion for calculation of Certainty Equivalent with respect to the quadratic } \\
\text { utility function } 4 \text {. } 3 \text { mom and } 4 \text { mom columns denote the Certainty Equivalent with respect to } 3 \text { and } 4 \text { moments } \\
\text { based utility functions as in Jurczenko and Maillet (2005), where equal weights were added to all portfolio moments. } \\
\text { Source: authors. }\end{array}$} \\
\hline
\end{tabular}

Finally, we calculated Certainty Equivalent (CE) values for every portfolio in the sample, by comparing in first two columns rankings based upon only the first two moments of each portfolio and in the last two columns by adding the skewness and kurtosis preferences into account as well. In that way, the rankings of the portfolios are based upon all of the portfolio moments, since we assumed that investor's preferences depend upon first 4 moments. Although the "2 moments" portfolios had in general greater values of CEs for the first two moments, the last two columns indicate that the "3 moments" portfolios could be preferred over other ones. Although these portfolios had negative realized returns, in these scenarios the skewness and kurtosis had such preferable values that in the overall ranking of the portfolios, the rankings change. This is affected by investor's preferences and aversions towards each portfolio moment (in these two last scenarios it is assumed that every moment is equally weighted in the utility function). Since the " 3 moments" portfolios were not attractive based upon the return, risk and Sharpe ratio criteria, it could be said that these portfolios could be recommended to those investors who are more focused on higher moments of the portfolio rather than

3 Sharpe ratio was calculated based upon the 91 day Treasury bill interest rate of the Ministry of Finance (2018) in Croatia which was equal to $0.36 \%$ in the observed period.

4 Values of 1 and 2 were chosen based upon Guidolin and Guidolin and Timmermann (2008) who used 2, 5 and 10; Ang and Bekaert (2002) where authors used 5 and 10. Guidolin and Timmermann (2007) showed that the results of ranking are robust if the coefficient is in the interval $(0,20]$. Additionally, we calculated Certainty Equivalent for values 5 and 10 and the rankings remained the same. Quadratic utility function was chosen for the calculation of Certainty Equivalent due to results in Pulley (1981), Kroll et al. (1984) and Cremers et al. (2003) who compared the rankings of the quadratic utility function to other functional forms of investor's utility and the results showed that the differences were nonsignificant. 
risks and returns (especially returns since they were negative for the majority of cases). By excluding the " 3 moments" portfolios, again it can be seen that the " 2 moments" portfolios exhibit the greatest CEs in majority cases.

Finally, the simulated values of each portfolio from the maximization ${ }^{5}$ scheme in Table 3 were depicted on Figure 5 in order to see which scenario could have been beneficial for the investor. The "equally weighted" and "2 moments" portfolios could have achieved greatest returns for the investor if he had structured his portfolio based upon the GRA analysis in 2017. There exists the potential to form the portfolio based upon the GRA ranking, since several portfolios achieved greater values compared to the value of the original efficient frontier portfolio.

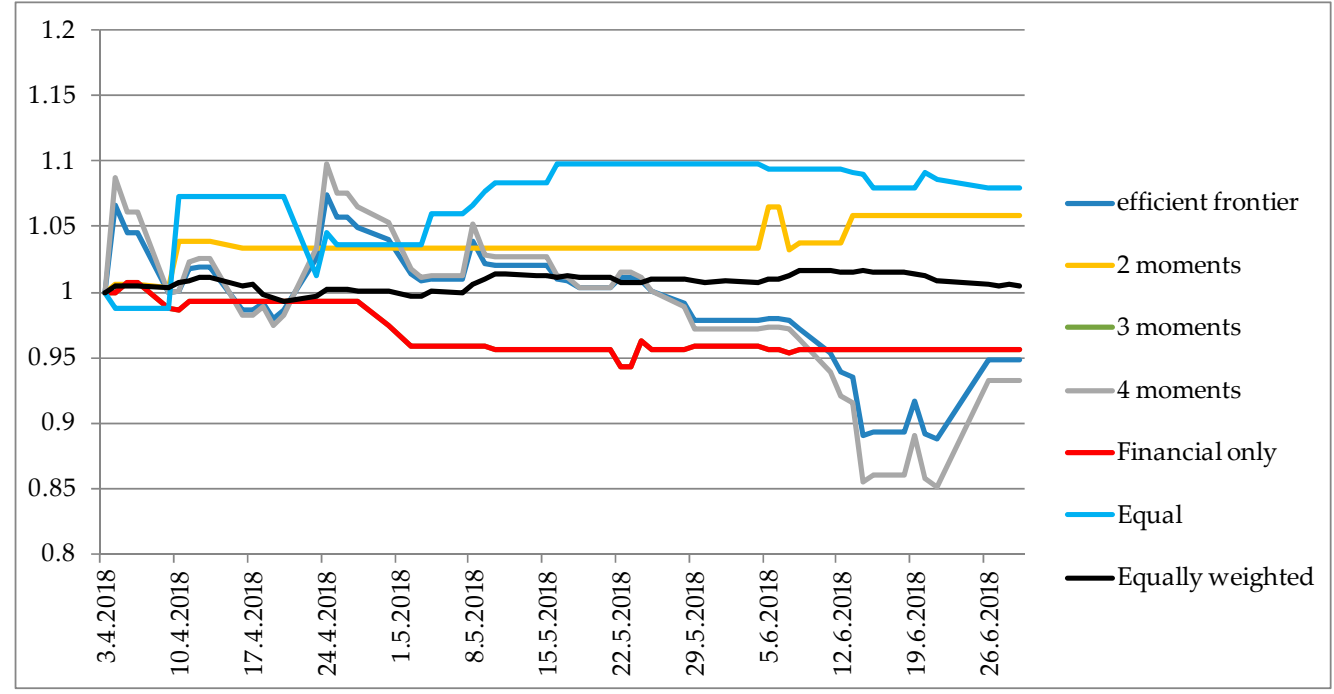

Figure 5. Simulated portfolio values for the case of maximizing the return portfolio.

\section{Discussion}

Based upon the results from the empirical analysis, several key points can be concluded. Firstly, both of the hypotheses can be confirmed. The first research question asked if GRA approach results can indicate a good portfolio structure. This was observed on Figures 3 and 4 and how the GRA portfolios moved towards the original efficient frontier. The resulting portfolios moved closer to the efficient frontier in cases where return distribution moments were taken into consideration. This is in line with previous empirical and theoretical research on the importance of distribution moments when investors make their decisions. The second question asked if portfolios resulting from GRA approach are better in terms of risk and return compared to the benchmark of the equally weighted portfolio. This was confirmed when both figures were commented, where it can be seen that all of the GRA portfolios had greater returns for the same value of risk and had lower risk with the same level or portfolio return. Moreover, these two questions were further explored in the out of sample analysis where, based upon the results in 2017, we simulated 25 portfolio scenarios in order to obtain risks, returns and other measures (in Table 3). Next, the potential of this analysis can be seen in many different scenarios which can be simulated before making investment decisions. Here, we observed only about a dozen of different scenarios in which investors can observe how the characteristics of portfolios change by changing the structure of the portfolio based upon the GRA approach. Thus, future work can be extended upon developing reliable criteria and scenarios. Future work will extend this research as well by including partial moments of return distributions to see whether concepts from Post Modern

5 Maximization of portfolio return problems were chosen since these portfolios could have enabled an investor to achieve the best results in terms of return series. Other 3 scenarios from Table 3 are omitted, but are available upon request; the portfolio values have similar relations one to another. 
Portfolio theory could result in better portfolio characteristics. Moreover, a dynamic analysis will be observed to see how factor changes over time influence portfolio selection and restructuring. Finally, different risk aversions will be included in the analysis as well, in order to obtain more insights into investor's decision making based upon their risk aversion as well.

\section{Conclusions}

With many data available today on financial markets, many factors influence the decision making process when making investment decisions. Quantitative methods and models are constantly being developed in order to facilitate the portfolio and risk management process. The goal of this study was to investigate how results from GRA affect portfolio construction. The results were compared to the original efficient frontier constructed based upon Markowitz portfolio optimization.

Some of the pitfalls of the study were as follows. We observed only the full moments of return distributions and not partial moments (such as lower partial risk measures, etc.). Moreover, a static analysis was conducted due to observing the entire year 2017 characteristics of return distributions. In that way, it was possible to carry out the out of sample analysis only for the first half of 2018. However, a dynamic analysis could be provided only on a quarterly basis as well if all of the firms provide quarterly financial statements. The monthly or a weekly basis of the analysis could be possible only with market data. Some subjectivity is always present when making decisions based upon several criteria. This was the case in this study as well, when investor has to choose the weights on the factors in the GRA analysis, as well as when ranking the portfolios based upon their risk aversion, skewness preference and/or kurtosis aversion. We cannot discuss the usefulness of specific moments or financial ratios when ranking stocks, due to this being an empirical problem. This means that some factors used in the analysis can change over time and affect the ranking. In that way, dynamic analysis should be provided when applying this in practice. In this specific example, it is not advised to use financial ratios in the analysis, due to the efficient frontier being lower compared to other ones and being very short (i.e., small, providing less investment possibilities compared to other approaches).

Finally, since the results showed the potential of this methodology, there is hope that further applications will extend to achieving even better results in portfolio selection. However, the contribution of this research can be found in initial analysis of the GRA approach when making investment decisions.

Author Contributions: All authors contributed equally.

Funding: This research received no external funding. The APC was funded by institutions through the Knowledge Unlatched initiative and partially funded by MDPI.

Acknowledgments: The authors would like to thank three anonymous referees for their valuable comments and suggestions which contributed to the quality of the paper.

Conflicts of Interest: The authors declare no conflict of interest.

\section{Appendix A}

Table A1. Factors used in the analysis with corresponding desirable values.

\begin{tabular}{lll}
\hline Return Distribution: & Market: & Financial Ratios: \\
\hline & & Book to market ratio (BM) + \\
& & Price to earnings ratio (PE) + \\
Expected return (ER) + & Return on assets (ROA) + \\
Standard deviation (SD) - & Trading volume (TV) - & Return on equity (ROE) + \\
Coefficient of asymmetry (CA) + & Number of transactions (NT) - & Earnings per share (EPS) + \\
Coefficient of skewness (CS) - & & Total business efficiency ratio (TBR) + \\
& & Asset turnover ratio (ATR) + \\
& & Dividends per share (DPS) + \\
\hline
\end{tabular}

Source: authors. 
Table A2. Stocks included in the analysis.

\begin{tabular}{|c|c|c|c|c|c|c|c|}
\hline $\mathrm{ADPL}^{\mathrm{h}}$ & ADRS $p$ & ADRS2 $p$ & $\mathrm{ARNT}^{1}$ & ATGR $^{j}$ & $\operatorname{ATLN}^{\circ}$ & ATPL k & $\mathrm{AUHR}^{\mathrm{j}}$ \\
\hline BD62 ${ }^{b}$ & BLJE $^{a}$ & $\mathrm{CKML}^{\mathrm{b}}$ & DDJH ${ }^{p}$ & DLKV $^{\mathrm{i}}$ & $\mathrm{ERNT}^{\mathrm{f}}$ & HDEL $^{\mathrm{i}}$ & HHLD $^{1}$ \\
\hline $\mathrm{HMST}^{1}$ & $\mathrm{HT}^{\mathrm{m}}$ & HUPZ $^{1}$ & $\mathrm{IGH}^{\mathrm{q}}$ & INA $^{d}$ & INGR $\mathrm{p}$ & IPKK $^{b}$ & JDGT $^{\mathrm{k}}$ \\
\hline $\mathrm{JDPL}^{\mathrm{k}}$ & $\mathrm{JMNC}^{\mathrm{b}}$ & $\mathrm{JNAF}^{\mathrm{k}}$ & KOEI $g$ & KRAS $^{b}$ & LEDO $^{b}$ & LHRC $^{1}$ & $\mathrm{LKPC}^{\mathrm{k}}$ \\
\hline LKRI $^{\mathrm{k}}$ & $\mathrm{LPLH}^{\mathrm{k}}$ & $\mathrm{LRH}{ }^{1}$ & MAIS $^{l}$ & MDKA $^{j}$ & OPTE $^{m}$ & $\mathrm{PLAG}^{1}$ & PODR $^{b}$ \\
\hline PTKM $^{\text {e }}$ & RIVP $^{1}$ & $\mathrm{RIZO}^{\mathrm{f}}$ & SAPN $^{\mathrm{e}}$ & SLRS $^{1}$ & THNK $^{\mathrm{i}}$ & $\mathrm{TPNG}^{\mathrm{k}}$ & TUHO $^{1}$ \\
\hline ULPL k & $\mathrm{ULJN}^{\mathrm{h}}$ & VART $^{c}$ & VIRO $^{b}$ & VLEN $^{h}$ & $\mathrm{ZB}^{\mathrm{n}}$ & $\mathrm{ZVZD}^{\mathrm{b}}$ & 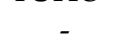 \\
\hline
\end{tabular}

Source: ZSE (2018). Note: sector classification of the stocks is as follows: ${ }^{\text {a }}$-agriculture, forestry and fishery;

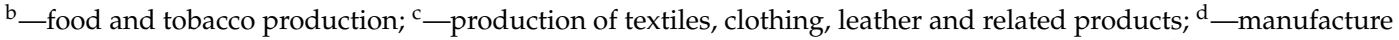
of coke and refined petroleum products; ${ }^{\mathrm{e}}$-manufacture of chemicals and chemical products; ${ }^{\mathrm{f}}$-manufacture of computers and electronic and optical products; $\mathrm{g}$-manufacture of electrical equipment; ${ }^{\mathrm{h}}$-manufacture of transport equipment; ${ }^{\mathrm{i}}$ - construction; ${ }^{j}$ - -wholesale and retail trade; repair of motor vehicles and motorcycles; ${ }^{k}$ - transport and storage; ${ }^{1}$-activities of providing accommodation and preparation and serving of food; ${ }^{\mathrm{m}}$ - telecommunications; $\mathrm{n}$-financial and insurance activities; ${ }^{\circ}$-real estate business; $\mathrm{P}$-legal, accounting, management, architectural and engineering engineering and technical testing and analysis; $\mathrm{q}$ - scientific research and development. Thus, in total 17 out of 23 sectors are included in the analysis.

Table A3. Ranking of stocks in the analysis.

\begin{tabular}{|c|c|c|c|c|c|c|c|c|}
\hline Stock. & $p=0.5$ & $2 \mathrm{mom}$ & $4 \mathrm{mom}$ & $3 \mathrm{mom}$ & Only Financial & 0.7 mom; 0.3 other & Risk & Return \\
\hline ADPL & 24 & 6 & 7 & 12 & 26 & 9 & 10 & 12 \\
\hline ADRS & 18 & 21 & 17 & 26 & 35 & 20 & 13 & 34 \\
\hline ADRS2 & 34 & 17 & 10 & 19 & 34 & 14 & 14 & 38 \\
\hline ARNT & 26 & 22 & 18 & 25 & 24 & 22 & 24 & 32 \\
\hline ATGR & 21 & 18 & 13 & 17 & 36 & 15 & 20 & 19 \\
\hline ATLN & 3 & 14 & 9 & 14 & 6 & 2 & 18 & 5 \\
\hline ATPL & 38 & 4 & 1 & 8 & 40 & 6 & 37 & 2 \\
\hline AUHR & 33 & 35 & 43 & 43 & 38 & 43 & 30 & 49 \\
\hline BD62 & 36 & 49 & 47 & 52 & 14 & 46 & 43 & 51 \\
\hline BLJE & 49 & 53 & 52 & 21 & 5 & 52 & 54 & 48 \\
\hline CKML & 17 & 2 & 29 & 5 & 37 & 27 & 2 & 26 \\
\hline DDJH & 53 & 51 & 48 & 53 & 43 & 49 & 48 & 53 \\
\hline DLKV & 52 & 32 & 16 & 29 & 32 & 34 & 40 & 23 \\
\hline ERNT & 32 & 16 & 21 & 18 & 31 & 25 & 21 & 28 \\
\hline HDEL & 39 & 46 & 44 & 48 & 50 & 45 & 45 & 41 \\
\hline HHLD & 43 & 44 & 37 & 45 & 55 & 39 & 39 & 43 \\
\hline HMST & 12 & 5 & 20 & 3 & 15 & 18 & 11 & 6 \\
\hline HT & 45 & 8 & 4 & 6 & 20 & 17 & 9 & 39 \\
\hline HUPZ & 46 & 31 & 55 & 47 & 18 & 54 & 33 & 40 \\
\hline IGH & 47 & 48 & 49 & 50 & 42 & 50 & 52 & 27 \\
\hline INA & 14 & 15 & 19 & 15 & 25 & 19 & 17 & 16 \\
\hline INGR & 51 & 39 & 27 & 37 & 33 & 38 & 46 & 22 \\
\hline IPKK & 30 & 38 & 39 & 39 & 45 & 36 & 35 & 37 \\
\hline JDGT & 28 & 11 & 46 & 27 & 19 & 44 & 6 & 33 \\
\hline JDPL & 41 & 47 & 42 & 51 & 44 & 41 & 47 & 47 \\
\hline JMNC & 27 & 50 & 51 & 34 & 9 & 48 & 51 & 21 \\
\hline JNAF & 8 & 12 & 33 & 4 & 11 & 26 & 4 & 17 \\
\hline KOEI & 11 & 13 & 6 & 13 & 28 & 5 & 12 & 11 \\
\hline KRAS & 15 & 23 & 14 & 24 & 17 & 13 & 16 & 30 \\
\hline LEDO & 55 & 55 & 54 & 49 & 54 & 55 & 55 & 55 \\
\hline LHRC & 9 & 3 & 3 & 7 & 21 & 3 & 26 & 3 \\
\hline LKPC & 6 & 19 & 15 & 16 & 8 & 8 & 7 & 14 \\
\hline LKRI & 4 & 29 & 26 & 28 & 7 & 16 & 27 & 10 \\
\hline LPLH & 5 & 20 & 34 & 23 & 4 & 23 & 8 & 13 \\
\hline LRH & 7 & 9 & 5 & 11 & 12 & 4 & 3 & 8 \\
\hline MAIS & 13 & 24 & 12 & 20 & 22 & 11 & 23 & 20 \\
\hline MDKA & 2 & 25 & 28 & 22 & 2 & 12 & 15 & 7 \\
\hline OPTE & 54 & 37 & 31 & 36 & 49 & 42 & 42 & 42 \\
\hline PLAG & 10 & 10 & 11 & 9 & 16 & 7 & 5 & 9 \\
\hline PODR & 16 & 33 & 22 & 33 & 10 & 21 & 25 & 44 \\
\hline PTKM & 50 & 52 & 53 & 54 & 48 & 53 & 50 & 52 \\
\hline
\end{tabular}


Table A3. Cont.

\begin{tabular}{|c|c|c|c|c|c|c|c|c|}
\hline Stock. & $p=0.5$ & $2 \mathrm{mom}$ & $4 \mathrm{mom}$ & $3 \mathrm{mom}$ & Only Financial & 0.7 mom; 0.3 other & Risk & Return \\
\hline RIVP & 42 & 7 & 2 & 10 & 3 & 10 & 22 & 18 \\
\hline RIZO & 31 & 43 & 40 & 46 & 51 & 40 & 34 & 50 \\
\hline SAPN & 23 & 34 & 36 & 38 & 27 & 31 & 31 & 24 \\
\hline SLRS & 22 & 27 & 41 & 35 & 13 & 35 & 28 & 31 \\
\hline THNK & 48 & 54 & 50 & 55 & 41 & 51 & 49 & 54 \\
\hline TPNG & 19 & 30 & 23 & 31 & 39 & 24 & 19 & 45 \\
\hline TUHO & 1 & 1 & 8 & 2 & 1 & 1 & 1 & 4 \\
\hline ULPL & 29 & 41 & 24 & 41 & 23 & 28 & 38 & 25 \\
\hline ULJN & 40 & 45 & 45 & 44 & 52 & 47 & 44 & 29 \\
\hline VART & 25 & 36 & 30 & 32 & 46 & 30 & 32 & 35 \\
\hline VIRO & 35 & 42 & 38 & 42 & 47 & 37 & 36 & 46 \\
\hline VLEN & 44 & 40 & 32 & 40 & 30 & 33 & 41 & 15 \\
\hline ZB & 37 & 26 & 25 & 30 & 53 & 29 & 29 & 36 \\
\hline ZVZD & 20 & 28 & 35 & 1 & 29 & 32 & 53 & 1 \\
\hline
\end{tabular}

\section{References}

Ang, Andrew, and Geert Bekaert. 2002. International Asset allocation With Regime Shifts. Review of Financial Studies 15: 1137-87. [CrossRef]

Arditti, Fred, and Haim Levy. 1975. Portfolio efficiency analysis in three moments: The multiperiod case. The Journal of Finance 303: 797-809. [CrossRef]

Arditti, Fred. 1967. Risk and the Required Return on Equity. The Journal of Finance 22: 19-36. [CrossRef]

Athayde, Gustavo, and Renato Galvão Flôres. 1997. A CAPM with Higher Moments: Theory and Econometrics. Discussion Paper EPGE-FGV. Rio de Janeiro: EPGE/FGV.

Banz, Rolf. 1981. The relationship between return and market value of common stocks. Journal of Financial Economics 9: 3-18. [CrossRef]

Basu, Sanjoy. 1977. The Investment Performance of Common Stocks in Relation to their Price to Earnings Ratio: A Test of the Efficient Markets Hypothesis. The Journal of Finance 32: 663-82. [CrossRef]

Briec, Walter, Kristiaan Kerstens, and Octave Jokung. 2006. Mean-variance-skewness portfolio performance gauging: A general shortage function and dual approach. Management Science 531: 135-49. [CrossRef]

Campbell, John, and Robert Shiller. 1988. The dividend-price ratio and expectations of future dividends and discount factors. Review of Financial Studies 1: 195-228. [CrossRef]

Campbell, John. 1987. Stock returns and the term structure. Journal of Financial Economics 18: 373-99. [CrossRef]

Cremers, Jan-Hein, Mark Kritzman, and Sebastian Page. 2003. Portfolio Formation with Higher Moments and Plausible Utility. In Revere Street Working Paper Series in Financial Economics 272-12. Cambridge: State Street Associates.

Chen, Hsing-Hung. 2008. Stock selection using data envelopment analysis. Industrial Management E Data Systems 108: 1255-68. [CrossRef]

Chen, Kung, and Shimerda Thomas. 1981. An Empirical Analysis of Useful Financial Ratios. Financial Management 10: 51-60. [CrossRef]

Datar, Vinay, Narayan Naik, and Robert Radcliffe. 1998. Liquidity and stock returns: An alternative test. Journal of Financial Markets 12: 203-19. [CrossRef]

Deng, Ju-Long. 1982. Control problems of Grey Systems. Systems and Control Letters 5: 288-94. [CrossRef]

Deng, Ju-Long. 1989. Introduction to Grey System Theory. The Journal of Grey Systems 1: 1-24.

Dia, Mohamm. 2007. A Portfolio Selection Methodology Based on Data Envelopment Analysis. INFOR: Information Systems and Operational Research 47: 71-79. [CrossRef]

Dimitropoulos, Panagiotis, and Dimitrios Asteriou. 2009. The Relationship between Earnings and Stock Returns: Empirical Evidence from the Greek Capital Market. International Journal of Economics and Finance 11: 40-50. [CrossRef]

Edirisinghe, Nalin Chanaka, and Xin Zhang. 2007. Generalized DEA model of fundamental analysis and its application to portfolio optimization. Journal of Banking $\mathcal{E}$ Finance 31: 3311-35. [CrossRef] 
Fama, Eugene F., and Kenneth R. French. 1988. Dividend yields and expected stock returns. Journal of Financial Economics 22: 3-25. [CrossRef]

Fama, Eugene F., and Kenneth R. French. 1992. The Cross-Section of Expected Stock Returns. The Journal of Finance 47: 427-65. [CrossRef]

Fama, Eugene F., and Kenneth R. French. 1993. Common risk factors in the returns on stocks and bonds. Journal of Financial Economics 33: 3-56. [CrossRef]

Fama, Eugene F., and Kenneth R. French. 1995. Size and Book-to-Market Factors in Earnings and Returns. The Journal of Finance 50: 131-55. [CrossRef]

Fama, Eugene F., and Kenneth R. French. 1996. Multifactor Explanations of Asset Pricing Anomalies. The Journal of Finance 51: 55-84. [CrossRef]

Fama, Eugene F., and William Schwert. 1977. Asset returns and inflation. Journal of Financial Economics 5: 115-46. [CrossRef]

Gardijan, Margareta, and Tihana Škrinjarić. 2015. Estimating investor preferences towards portfolio return distribution in investment funds. Croatian Operational Research Review 62: 1-16. [CrossRef]

Guidolin, Massimo, and Allan Timmermann. 2007. Asset allocation under multivariate regime switching. Journal of Economic Dynamics and Control 31: 3503-44. [CrossRef]

Guidolin, Massimo, and Allan Timmermann. 2008. International Asset allocation under Regime Switching, Skew, and Kurtosis Preferences. The Review of Financial Studies 21: 889-935. [CrossRef]

Huang, Kuang Yu, and Chuen-Jiuan Jane. 2008. An Automatic Stock Market Forecasting and Portfolio Selection Mechanism Based on VPRS, ARX and Grey System. Paper presented at IEEE Asia-Pacific Services Computing Conference, Yilan, Taiwan, December 9-12.

Huang, Kuang Yu, Chuen-Jiuan Jane, and Ting-Cheng Chang. 2008. A RS Model for Stock Market Forecasting and Portfolio Selection Allied with Weight Clustering and Grey System Theories. Paper presented at IEEE Congress on Evolutionary Computation, CEC 2008, Hong Kong, China, June 1-6, pp. 1240-46. [CrossRef]

Hur, Seok-Kyun, Chune Young Chung, and Chang Liu. 2018. Is Liquidity Risk Priced? Theory and Evidence. Sustainability 10: 1809. [CrossRef]

Hur, Seok-Kyun, and Chune Young Chung. 2018. A novel measure of liquidity premium: Application to the Korean stock market. Applied Economics Letters 25: 211-15. [CrossRef]

Hwang, Soosung, and Stephen Satchell. 1999. Modeling emerging market risk premia using higher moments. International Journal of Finance and Economics 44: 271-96. [CrossRef]

Jane, Chuen-Jiuan, and Yu Kuang Huang. 2013. A Fusion Model for Stock selection Based on Decision Tree, Artificial Neural Network and Grey Relational Analysis. International Journal of Kansei Information 4: 115-22.

Jondeau, Eric, and Michael Rockinger. 2006. Optimal portfolio allocation under higher moments. European Financial Management 121: 29-55. [CrossRef]

Jurczenko, Emmanuel, and Bertrand Maillet. 2005. The Four-moment Capital Asset Pricing Model: Between Asset Pricing and Asset Allocation. In Multi-Moment Asset Allocation and Pricing Models. New York: John Wiley and Sons.

Knight, John, and Stephen Satchell. 2002. Performance Measurement in Finance. Oxford: Elsevier Science Ltd.

Korzeniewski, Jerzy. 2018. Efficient Stock Portfolio Construction by Means of Clustering. Folia Oeconomica 1: 85-92. [CrossRef]

Kothari, Smitu P., and Jay Shanken. 1997. Book-to-market, dividend yield, and expected market returns: A time series analysis. Journal of Financial Economics 44: 169-203. [CrossRef]

Kroll, Yoram, Haim Levy, and Harry Markowitz. 1984. Mean-Variance Versus Direct Utility Maximization. The Journal of Finance 39: 47-61. [CrossRef]

Kuo, Yiyo, Taho Yang, and Guan-Wei Huang. 2008. The use of a grey-based Taguchi method for optimizing multi-response simulation problems. Engineering Optimization 40: 517-28. [CrossRef]

Lewellen, Jonathan. 2004. Predicting returns with financial ratios. Journal of Financial Economics 742: 209-35. [CrossRef]

Li, Hong-Yi, Chu Zhang, and Di Zhao. 2010. Stock Investment Value Analysis Model Based on AHP and Grey Relational Degree. Management Science and Engineering 4: 1-6.

Liu, Sifeng, and Yi Lin. 2006. Grey Information Theory and Practical Applications. New York: Springer.

Liu, Sifeng, and Yi Lin. 2010. Grey Systems, Theory and Applications. Berlin/Heidelberg: Springer. 
Liu, Sifeng, Yingjie Yang, and Jeffery Forrest. 2016. Grey Data Analysis: Methods, Models and Applications. Singapore: Springer Science + Business Media.

Liu, Weimin. 2006. A liquidity-augmented capital asset pricing model. Journal of Financial Economics 823: 631-71. [CrossRef]

Markowitz, Harry. 1952. Portfolio Selection. The Journal of Finance 7: 77-91. [CrossRef]

Markowitz, Harry. 1959. Portfolio Selection: Efficient Diversification of Investments. New York: Wiley.

Ministry of Finance. 2018. Available online: https:/ /www.mfin.hr (accessed on 13 December 2018).

Mohammadi Pour, Rahmatollah, Zhaleh Alavimoghadam, and Adel Fatemi. 2016. Comparison of Selected Performance of Portfolio Investment Companies by Using of Grey Forecasting and Johnson's Index in Tehran Stock Exchange Market. Advances in Mathematical Finance \& Applications 1: 15-28.

Muhammad, Noor, and Frank Scrimgeour. 2014. Stock Returns and Fundamentals in the Australian Market. Asian Journal of Finance $\mathcal{E}$ Accounting 6: 271-90. [CrossRef]

Müller, Sigrid, and Mark Machina. 1987. Moment preferences and polynomial utility. Economics Letters 23: 349-53. [CrossRef]

Palepu, Krishna, and Paul Healy. 2010. Business Analysis E Valuation: Using Financial Statements, 4th ed. Nashville: South-Western College Pub.

Pástor, L'uboš, and Robert Stambaugh. 2003. Liquidity risk and expected stock returns. Journal of Political Economy 1113: 642-85. [CrossRef]

Pulley, Lawrence. 1981. A General Mean-Variance Approximation to Expected Utility for Short Holding Periods. Journal of Financial and Quantitative Analysis 16: 361-73. [CrossRef]

Reinganum, Marc. 1981. Misspecification of asset pricing: Empirical anomalies based on earnings yields and market values. Journal of Financial Economics 9: 19-46. [CrossRef]

Salardini, Firoozeh. 2013. An AHP-GRA method for asset allocation: A case study of investment firms on Tehran Stock Exchange. Decision Science Letters 2: 275-80. [CrossRef]

Shiller, Robert. 2005. Irrational Exuberance, 2nd ed. Princeton: Princeton University Press.

Singh, Arjun, and Raymond Schmidgall. 2002. Analysis of financial ratios commonly used by US lodging financial executives. Journal of Retail \& Leisure Property 2: 201-13. [CrossRef]

Steuer, Ralph, Yue Qi, and Markus Hirschberger. 2008. Portfolio Selection in the Presence of Multiple Criteria. In Handbook of Financial Engineering. New York: Springer Science, pp. 3-24.

Škrinjarić, Tihana. 2018a. Revisiting Herding Investment Behavior on the Zagreb Stock Exchange: A Quantile Regression Approach. Econometric Research in Finance 3: 119-62.

Škrinjarić, Tihana. 2018b. Testing for Seasonal Affective Disorder on Selected CEE and SEE Stock Markets. Risks 6: 140. [CrossRef]

Vidović, Jelena. 2013. Investigation of Stock Illiquidity on Central and South East European markets in Naive Portfolio Framework. Economic Thought and Practice 22: 537-50.

Wei, Guiwu. 2011. Grey Relational Analysis Model for Dynamic Hybrid Multiple Attribute Decision Making. Knowledge-Based Systems 24: 672-79. [CrossRef]

Wu, Liansheng. 2000. A Survey and An Analysis of Investor's Demands for Listed Companies' Accounting Information. Economic Research Journal 4: 41-48.

ZSE. 2018. Available online: https:/ / www.zse.hr (accessed on 1 November 2018).

(C) 2018 by the authors. Licensee MDPI, Basel, Switzerland. This article is an open access article distributed under the terms and conditions of the Creative Commons Attribution (CC BY) license (http://creativecommons.org/licenses/by/4.0/). 